Article

\title{
Probiotic Bacillus Spores Protect Against Acetaminophen Induced Acute Liver Injury in Rats
}

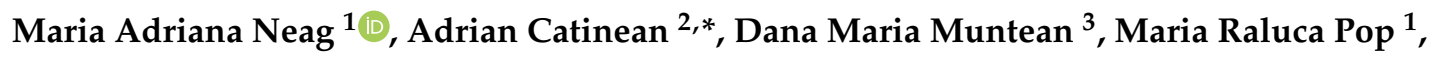 \\ Corina Ioana Bocsan ${ }^{1}$, Emil Claudiu Botan ${ }^{4}$ and Anca Dana Buzoianu ${ }^{1}$ \\ 1 Department of Pharmacology, Toxicology and Clinical Pharmacology, Iuliu Hatieganu University of \\ Medicine and Pharmacy, Cluj-Napoca 400337, Romania; maria.neag@umfcluj.ro (M.A.N.); \\ raluca_parlog@yahoo.com (M.R.P.); corinabocsan@yahoo.com (C.I.B.); abuzoianu@umfcluj.ro (A.D.B.) \\ 2 Department of Internal Medicine, Iuliu Hatieganu University of Medicine and Pharmacy, \\ Cluj-Napoca 400006, Romania \\ 3 Department of Pharmaceutical Technology and Biopharmaceutics, Iuliu Hatieganu University of Medicine \\ and Pharmacy, Cluj-Napoca 400010, Romania; dana@tbs.ubbcluj.ro \\ 4 County Emergency Hospital Cluj-Napoca, Cluj-Napoca 400006, Romania; botanemil@gmail.com \\ * Correspondence: catinean@gmail.com; Tel.: +40-752122466
}

Received: 6 February 2020; Accepted: 24 February 2020; Published: 27 February 2020

\begin{abstract}
Acetaminophen (APAP) is one of the most used analgesics and antipyretic agents in the world. Intoxication with APAP is the main cause of acute liver toxicity in both the US and Europe. Spore-forming probiotic bacteria have the ability to resist harsh gastric and intestinal conditions. The aim of this study was to investigate the possible protective effect of Bacillus (B) species (sp) spores (B. licheniformis, B. indicus, B. subtilis, B. clausii, B. coagulans) against hepatotoxicity induced by APAP in rats. A total of 35 rats were randomly divided into seven groups: group I served as control; group II received silymarin; group III received MegaSporeBiotic ${ }^{\mathrm{TM}}$ (MSB); group IV received APAP and served as the model of hepatotoxicity; group V received APAP and silymarin; group VI received APAP and MSB; group VII received APAP, silymarin and MSB. The livers for histopathological examination and blood samples were collected on the last day of the experiment. We determined aspartate aminotransferase (AST), alanine aminotransferase (ALT) and total antioxidant capacity (TAC) levels and zonula occludens (ZO-1), tumor necrosis factor $\alpha$ (TNF- $\alpha$ ) and interleukin $1 \beta$ (IL-1 $\beta$ ) expression. APAP overdose increased AST and ALT. It slowly decreased TAC compared to the control group, but pretreatment with silymarin and MSB increased TAC levels. Elevated plasma concentrations were identified for ZO-1 in groups treated with APAP overdose compared with those without APAP or receiving APAP in combination with silymarin, MSB or both. The changes were positively correlated with the levels of other proinflammatory cytokines (TNF- $\alpha$, IL-1 $\beta$ ). In addition, histopathological hepatic injury was improved by preadministration of MSB or silymarin versus the disease model group. Bacillus sp spores had a protective effect on acute hepatic injury induced by APAP. Pretreatment with MSB resulted in a significant reduction in serum AST, ALT, TNF- $\alpha$, IL- $1 \beta, Z \mathrm{ZO}-1$, TAC and also hepatocyte necrosis, similar to the well-known hepatoprotective agent-silymarin.
\end{abstract}

Keywords: Bacillus spores; acute hepatotoxicity; acetaminophen; tight junction; inflammation

\section{Introduction}

The liver is the main organ involved in maintaining the body's homeostasis. Many chemical compounds (including medicines) and herbal remedies, when used in overdose quantities, may cause liver damage [1]. Acetaminophen (N-acetyl-p-aminophenol or paracetamol; APAP), an over-the-counter drug, is one of the most used analgesics and antipyretic agents in the world [2]. It is known that in high 
doses, APAP may lead to acute liver failure [3]; intentional or unintentional intoxication with APAP is the main cause of acute liver toxicity in both the United States and Europe [2]. APAP, at the therapeutic dose, is metabolized mainly by glucuronidation and sulfation (phase II reactions) to nontoxic metabolites in the liver. A minor fraction of the therapeutic dose is oxidized by the CYP450 hepatic enzymes to the reactive metabolite N-acetyl-p-benzoquinone-imine (NAPQI). When APAP is taken in high doses, the amount of NAPQI increases significantly, which depletes hepatic glutathione (GSH) storage and results in increased oxidative stress and mitochondrial dysfunction with decreased adenosine triphosphate (ATP; e.g., mitochondrial dysfunction, oxidative stress, inflammatory reactions) [4-7]. Moreover, cell damage is also the consequence of activating mitogen-activated protein kinase (MAPK), c-Jun-N-terminal kinase (JNK) or nuclear DNA fragmentation [8].

Probiotics have been shown to have beneficial effects in several ailments, from gastrointestinal disorders (inflammatory bowel diseases, liver diseases) to allergy, metabolic disorders and cancer. These effects are a consequence of restoring the balance of gut microbiota (commensal vs. pathogenic bacteria), maintaining the integrity of the intestinal barrier, reducing the production of toxic products and improving the liver function [9-11]. The beneficial effect of probiotics may be due to the inhibition of growth of harmful bacteria by the production of free fatty acids, hydrogen peroxide and antimicrobial peptides $[12,13]$.

Bacillus species (sp) are characterized by a high level of resistance to physical and chemical agents that are normally considered harmful to microorganisms (heat, toxic chemicals, radiation) [14]. Moreover, spores have a greater resistance to technological stress and storage compared to vegetative/active probiotics. They also have the ability to resist harsh gastric and intestinal conditions (bile acids, digestive enzymes, $\mathrm{pH}$ ) [15]. Thus, spore-forming probiotic bacteria are considered a very good alternative solution to replace Bifidobacterium and Lactobacillus strains, which have the disadvantage of low stability [16,17]. The aforementioned advantages of using Bacillus can explain recent efforts to open up new perspectives on the use of spore-based probiotics, which exhibit similar stability to other pharmaceutical drugs used for conventional treatment of many diseases [18].

This study was performed to evaluate the possible protective effect of Bacillus sp. spores (B. licheniformis, B. indicus, B. subtilis, B. clausii, B. coagulans) on acute hepatic injury induced by APAP overdose in rats.

\section{Materials and Methods}

\subsection{Drugs and Chemicals}

We used MegaSporeBiotic ${ }^{\mathrm{TM}}$ (MSB) probiotic capsules (Microbiome Labs, Saint Augustine, FL, USA) and two standard commercial compounds, silymarin (150 mg/tablet) and APAP (500 mg/tablet; uncoated tablets). All products were purchased from a public pharmacy and administered as a suspension with $1 \%$ carboxymethylcellulose (CMC) as the vehicle. MSB is a probiotic blend of spores from five Bacillus species (B. licheniformis, B. indicus, B. subtilis, B. clausii and B. coagulans).

\subsection{Animals}

Charles River Wistar white male rats $(n=35)$ weighing between 250 and 280 g were obtained from the Center for Experimental Medicine and Practical Skills of the university. The working animal protocol was revised and approved by the Ethics Committee of Iuliu Haţieganu University of Medicine and Pharmacy, nr. 12101/02.05.2018.

The rats were kept in cages in a clean room with $12 \mathrm{~h}$ light/dark cycles and a temperature of $22 \pm 2{ }^{\circ} \mathrm{C}$. The animals were acclimated under these conditions for two days prior to starting the experiment. Specific regulations and amendments from this study were from the "Guiding Principles in the Use of Animals in Toxicology" adopted by the Society of Toxicology (Reston, VA, USA) and the national law regarding the protection of animals used for scientific research. 


\subsection{Experimental Design}

A total of 35 rats were randomly divided into seven groups ( $n=5 /$ group): group I served as control and received only the vehicle, $1 \%$ CMC; group II received silymarin $(100 \mathrm{mg} / \mathrm{kg} /$ day $)$; group III received MSB $\left(1 \times 10^{9} \mathrm{CFU} /\right.$ day $)$; group IV received APAP $(2 \mathrm{~g} / \mathrm{kg})$ and served as the model of hepatotoxicity; group V received APAP $(2 \mathrm{~g} / \mathrm{kg})$ and silymarin $(100 \mathrm{mg} / \mathrm{kg} /$ day $)$; group VI received APAP $(2 \mathrm{~g} / \mathrm{kg})$ and MSB $\left(1 \times 10^{9} \mathrm{CFU} /\right.$ day $)$; group VII received APAP $(2 \mathrm{~g} / \mathrm{kg})$, silymarin $(100 \mathrm{mg} / \mathrm{kg} /$ day $)$ and MSB $\left(1 \times 10^{9} \mathrm{CFU} /\right.$ day $)$. All of the substances were suspended in $1 \% \mathrm{CMC}$. Animals were fed rat chow ad libitum and had free access to tap water.

CMC, silymarin and MSB were administered orally through a feeding tube daily for 12 days. Groups IV, V, VI and VII received a single dose of APAP suspended in 1\% CMC on day 11, also administered orally through a feeding tube.

Blood was collected from the retro-orbital sinus plexus under mild ether anesthesia (periorbital method) on the last day of the experiment (48 h after receiving APAP; Day 13). After coagulation, the serum was separated by centrifuging at $4000 \mathrm{rpm}$ for $15 \mathrm{~min}$; the serum was stored at $-20^{\circ} \mathrm{C}$ for further biochemical analysis.

Serum aspartate aminotransferase (AST) and alanine aminotransferase (ALT) were measured by an automatic biochemical analyzer according to the manufacturer's protocols; total antioxidant capacity (TAC) using a validated high-throughput liquid chromatography (HPLC) tandem mass spectrometry analytical method previously described by Erel [19], TNF- $\alpha$, IL-1 $\beta$ and zonula occludens (ZO-1) were measured using ELISA technique (Stat Fax 303 Plus Microstrip Reader, Minneapolis, USA). Their detection and quantification were performed using commercially available kits (TNF- $\alpha$ and IL-1 $\beta$ ABTS ELISA development kits; PeproTech EC, Ltd., London, UK; and TJP1 ELISA kit; Elabscience, Houston, TX, USA). Animals were sacrificed with xylazine/ketamine overdose.

\subsection{Histopathological Examination}

At the end of the study, the liver of each animal was removed and excised tissue sections were preserved in $10 \%$ formaldehyde, dehydrated in graduated ethanol and embedded in paraffin. Embedded liver tissues were cut into $7 \mu \mathrm{m}$ sections using a microtome (RM 2145; Leica, Wetzlar, Germany) then mounted on glass slides. Slides were stained with hematoxylin-eosin for histological evaluation. The histological sections were examined using a Leica DM2500 LED microscope and the images were captured using a Leica DMC2900 (Leica Microsystems Ltd., Heerbrugg, Switzerland) camera which was connected to the microscope.

\subsection{Statistical Analysis}

All data were presented as mean \pm standard deviation (SD). The significance between the different groups was analyzed by one-way ANOVA. SPSS 10.0 statistical software (SPSS Inc., Chicago, IL, USA) was used for all statistical analyses. A $p$-value $<0.05$ was considered statistically significant.

\section{Results}

\subsection{Effect of MegaSporeBiotic ${ }^{\mathrm{TM}}$ and Silymarin on Liver Functions}

Administration of APAP caused a significant elevation in serum liver enzymes (ALT, AST) (ALT, $p=0.017$, AST, $p=0.007$; group I vs. group IV). Pretreatment with silymarin (ALT, $p=0.009$; AST, $p=0.016$; group V vs. group IV), MSB (ALT, $p=0.007$; AST, $p=0.013$; group VI vs. group IV) or both (ALT, $p=0.04$; AST, $p=0.015$; group VII vs. group IV) significantly alleviated the hepatotoxic effect of APAP (Figure 1A,B). No significant differences were found between rats treated with silymarin and rats treated with MSB or both MSB and silymarin. 
AST (IU/L)

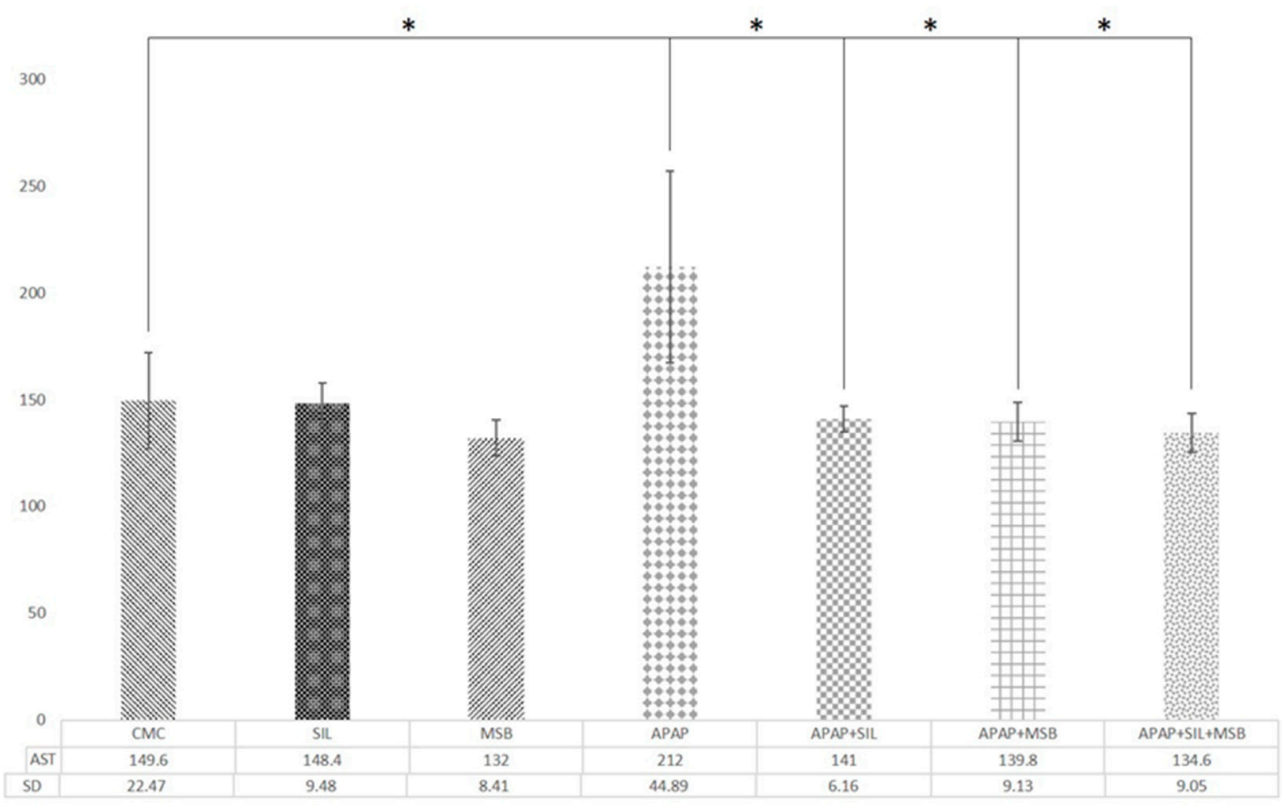

(A) Changes in AST levels.

ALT (IU/L)

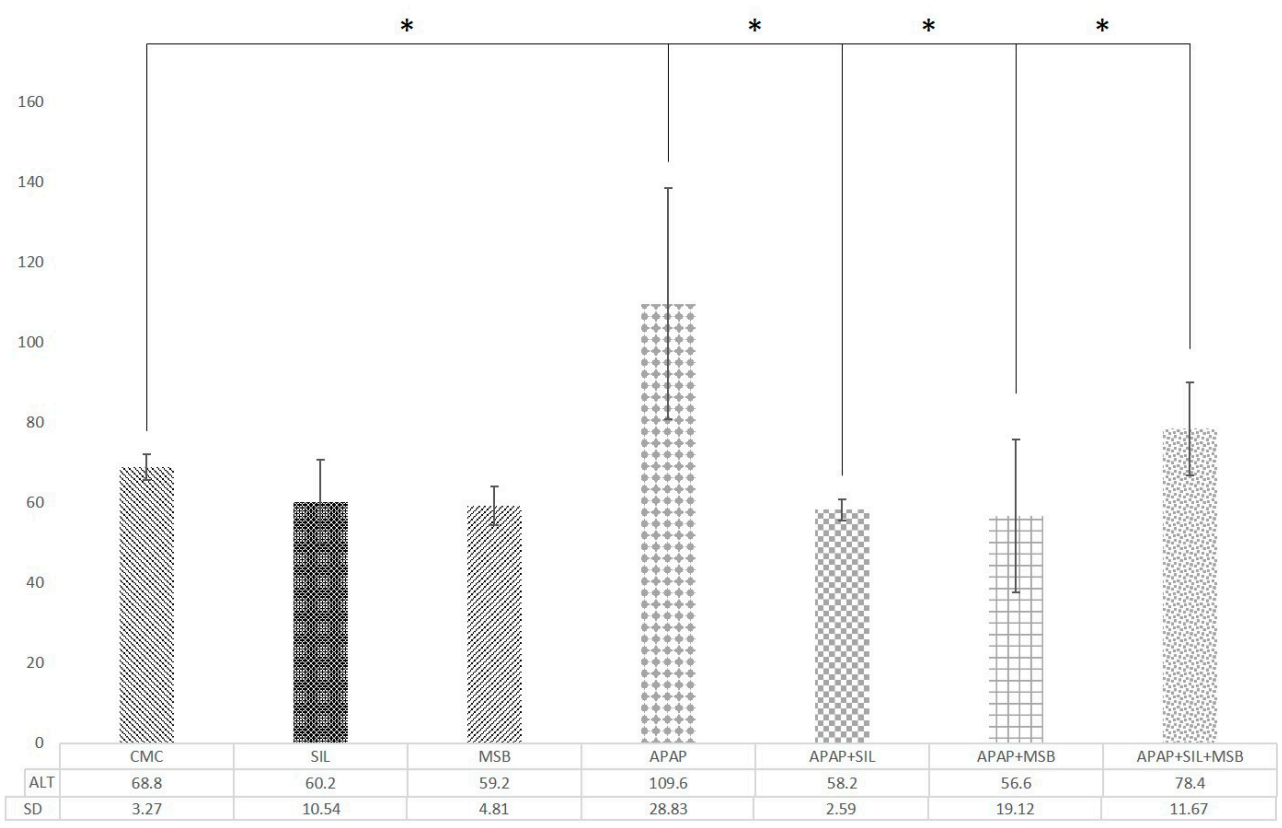

(B) Changes in ALT levels.

Figure 1. Changes in AST (dotted) and ALT (lined) levels. Rats were treated with $1 \%$ CMC, APAP, MSB or SIL either alone or in various combinations (as indicated). Periorbital blood was collected on Day 13, and the serum was tested for AST and ALT levels. * Significant difference $(p<0.05)$ between groups; data were analyzed using one-way ANOVA. Abbreviations: ALT, alanine aminotransferase; AST, aspartate aminotransferase; APAP, N-acetyl-p-aminophenol or paracetamol (acetaminophen); CMC, carboxymethylcellulose; MSB, MegaSporeBiotic ${ }^{\mathrm{TM}}$; SIL, silymarin. 
3.2. Effect of MegaSporeBiotic ${ }^{\mathrm{TM}}$ and Silymarin on Inflammation and Oxidative Stress

APAP determined marked an increase in the levels of proinflammatory cytokines TNF- $\alpha$ and IL-1 $\beta$ compared with the control group $(p<0.05)$. MSB and silymarin significantly decreased inflammation (Figure 2A,B).

TNF- $\alpha(p g / m L)$

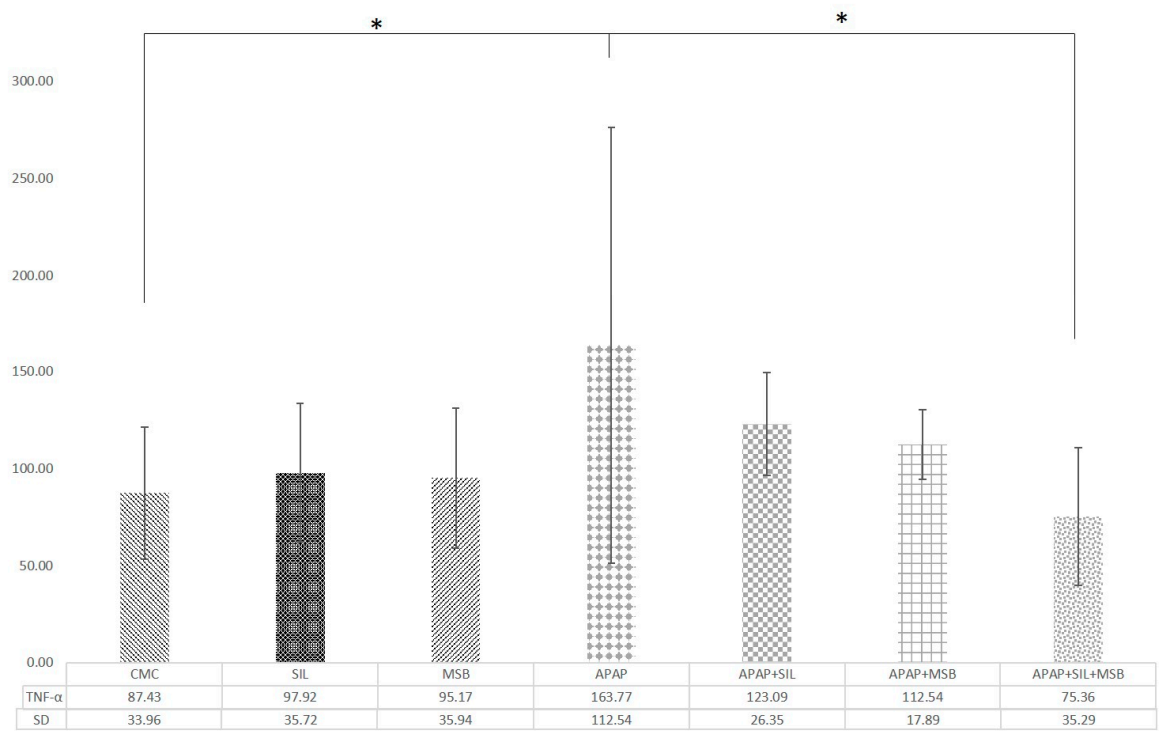

(A) Changes in TNF- $\alpha$ levels

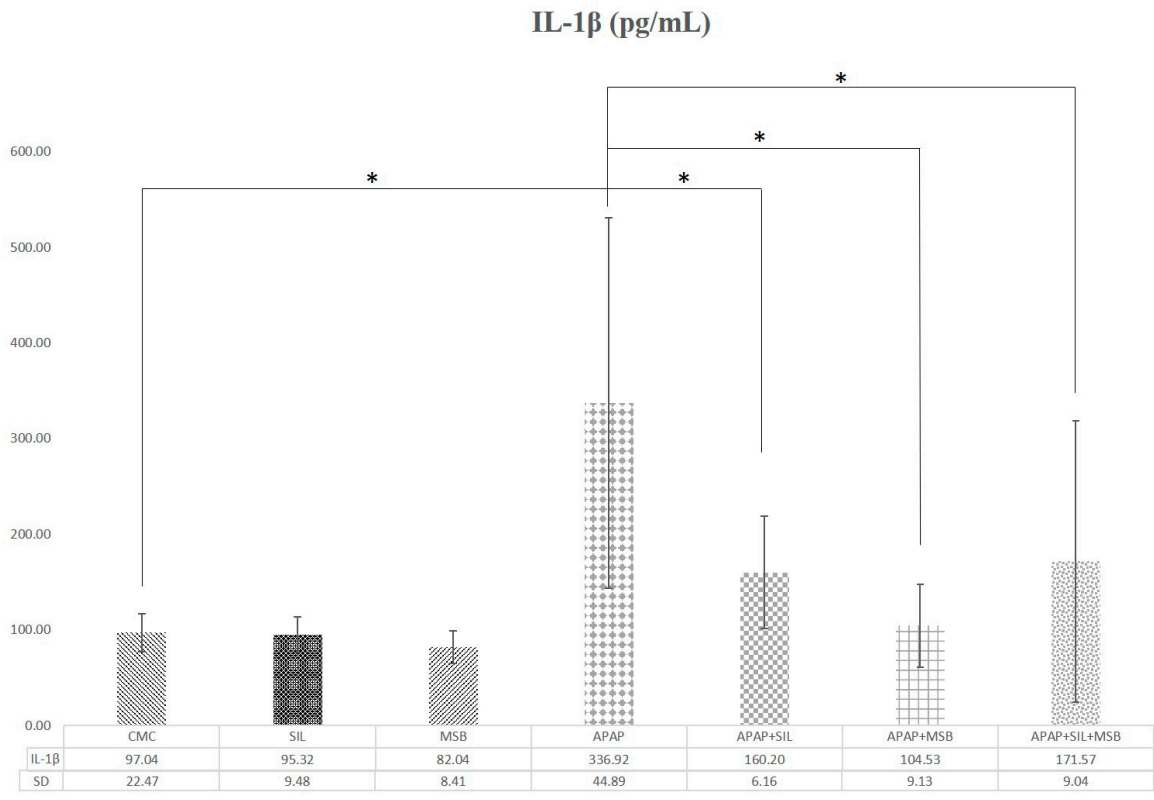

(B) Changes in IL-1 $\beta$ levels

Figure 2. Rats were treated with $1 \%$ CMC, SIL, MSB, APAP, APAP + SIL, APAP + MSB or APAP + SIL + MSB. Periorbital blood was collected on Day 13, and the serum was tested for TNF- $\alpha$ (A) and IL-1 $\beta($ B) levels. * Significant difference $(p<0.05)$ between groups; data were analyzed using one-way ANOVA. Abbreviations: APAP, N-acetyl-p-aminophenol or paracetamol (acetaminophen); CMC, carboxymethylcellulose; IL-1 $\beta$, interleukin $1 \beta$; MSB, MegaSporeBiotic ${ }^{\mathrm{TM}}$; SIL, silymarin; TNF- $\alpha$, tumoral necrosis factor $\alpha$. 
To investigate the antioxidant effect of MSB, the levels of TAC were determined in rats. APAP treatment significantly decreased the TAC compared with the control group $(p=0.012)$. MSB and silymarin administered resulted in a significant increase in TAC (Figure 3).

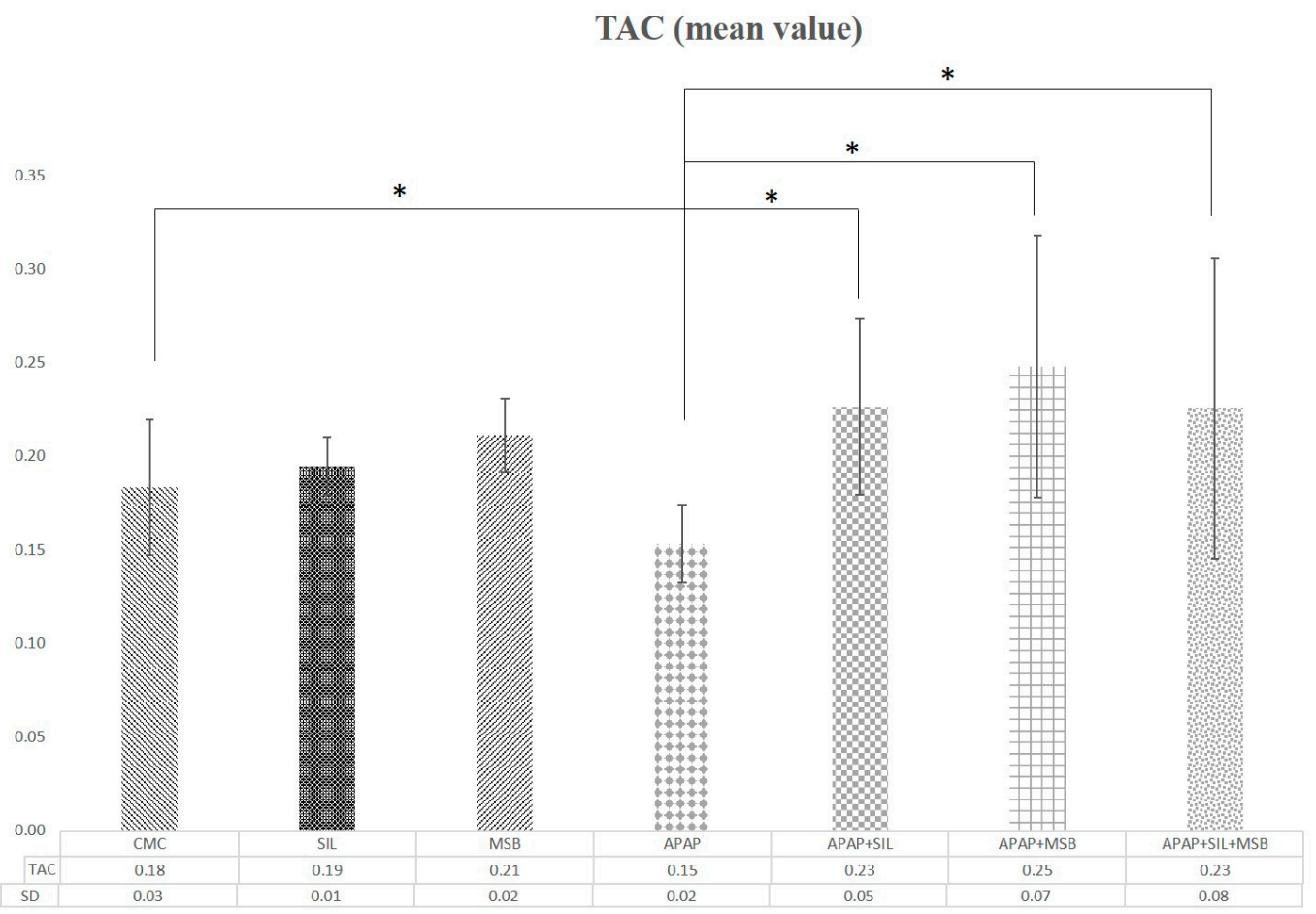

Figure 3. Changes in TAC levels. Rats were treated with $1 \%$ CMC, APAP, MSB or SIL either alone or in various combinations (as indicated). Periorbital blood was collected on Day 13, and the serum was tested for TAC levels. ${ }^{*}$ Significant difference $(p<0.05)$ between groups; data were analyzed using one-way ANOVA. Abbreviations: APAP, N-acetyl-p-aminophenol or paracetamol (acetaminophen); CMC, carboxymethylcellulose; MSB, MegaSporeBiotic ${ }^{\mathrm{TM}}$; TAC, total antioxidant capacity; TRL, Trolox; SIL, silymarin.

\subsection{Histopathology}

Examination of the histological architecture of the livers from groups I, II and III revealed that the tissue was normal (Figure 4A).

Examination of liver sections in group IV showed several histological changes in the liver structure. Focal hepatocellular necrosis, porto-central necrotic bridges ( $25 \%$ of the sectional area) and diffuse and circumferential pericentral hepatitis (all portal spaces) were observed in these livers (Figure 4B1,B2).

In group V, 11 of the 33 central veins examined presented adjacent hepatitis with around 2/3 of the circumference involved. Minimal perivenular hepatocyte dystrophy was observed in approximately $10 \%$ of the sectional area. All portal spaces had low eosinophil and lymphocyte inflammatory infiltrates and were without interface hepatitis (Figure 4C1,C2).

Liver sections from group VI showed that 2 of the 46 central veins viewed had mild adjacent hepatitis. Also, of the 13 portal spaces identified on the whole section, 6 had a low-level of eosinophilic and lymphocytic inflammation. A single portal space with mild interface hepatitis was identified. A single focus of lobular hepatitis was identified for the entire sectional area. Hepatocyte dystrophy was absent (Figure 4D1,D2).

In group VII, $50 \%$ of the central veins presented mild perivenular inflammation with eosinophils and lymphocytes, and $20 \%$ had moderate inflammation associated with perivenular hepatitis. Also, 
hepatocyte dystrophy was observed in about $20 \%$ of the sectional area and over $70 \%$ of portal spaces had few eosinophils and lymphocytes and no interface hepatitis was observed (Figure 4E1,E2).

Pretreatment with silymarin (group V), MSB (group VI) or both (group VII) significantly prevented changes in hepatic parenchyma compared to group IV, which was treated with APAP alone.

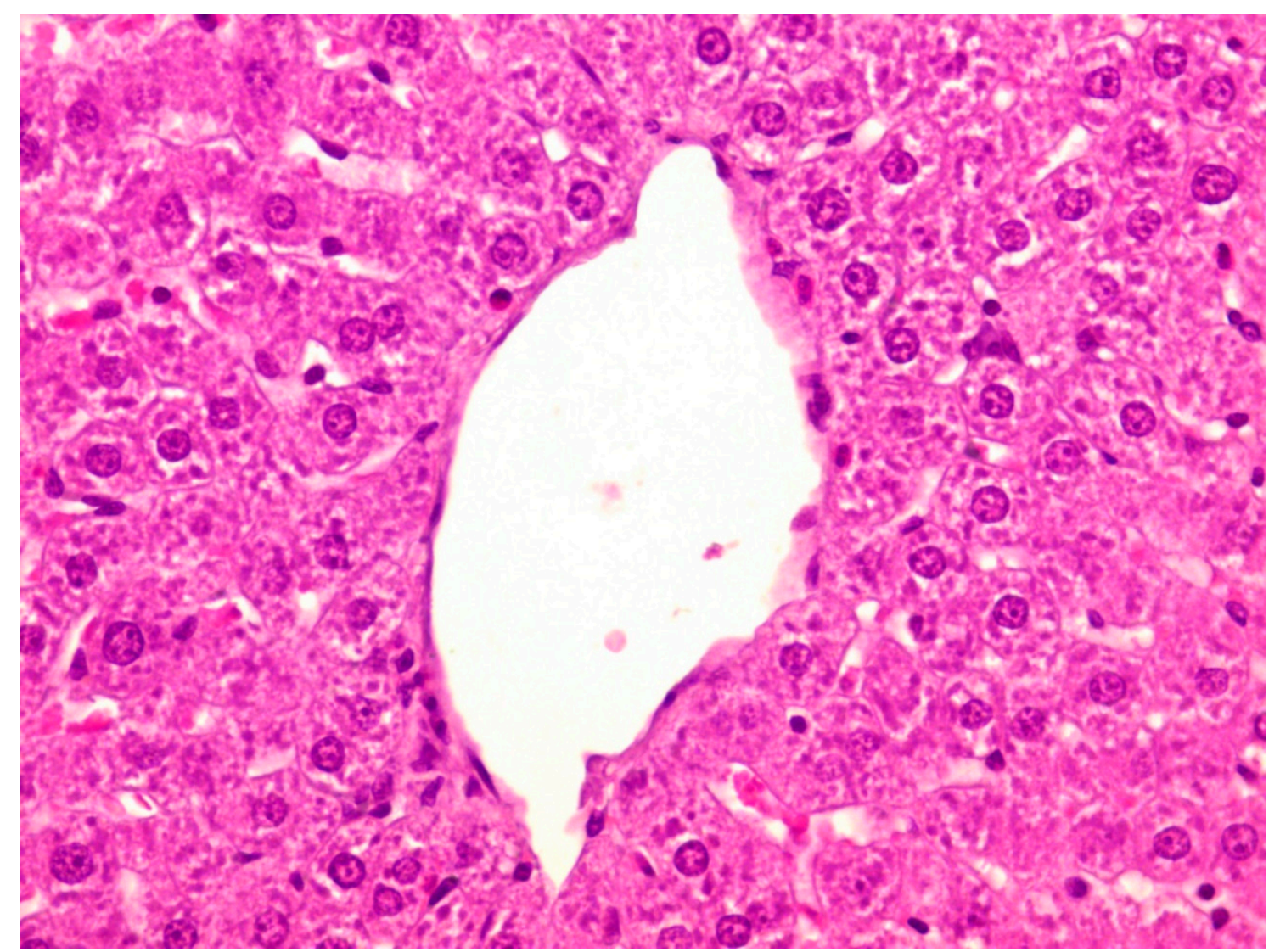

(A) The hepatic histological aspect of groups I, II, III; HE staining, 40×.

Figure 4. Cont. 


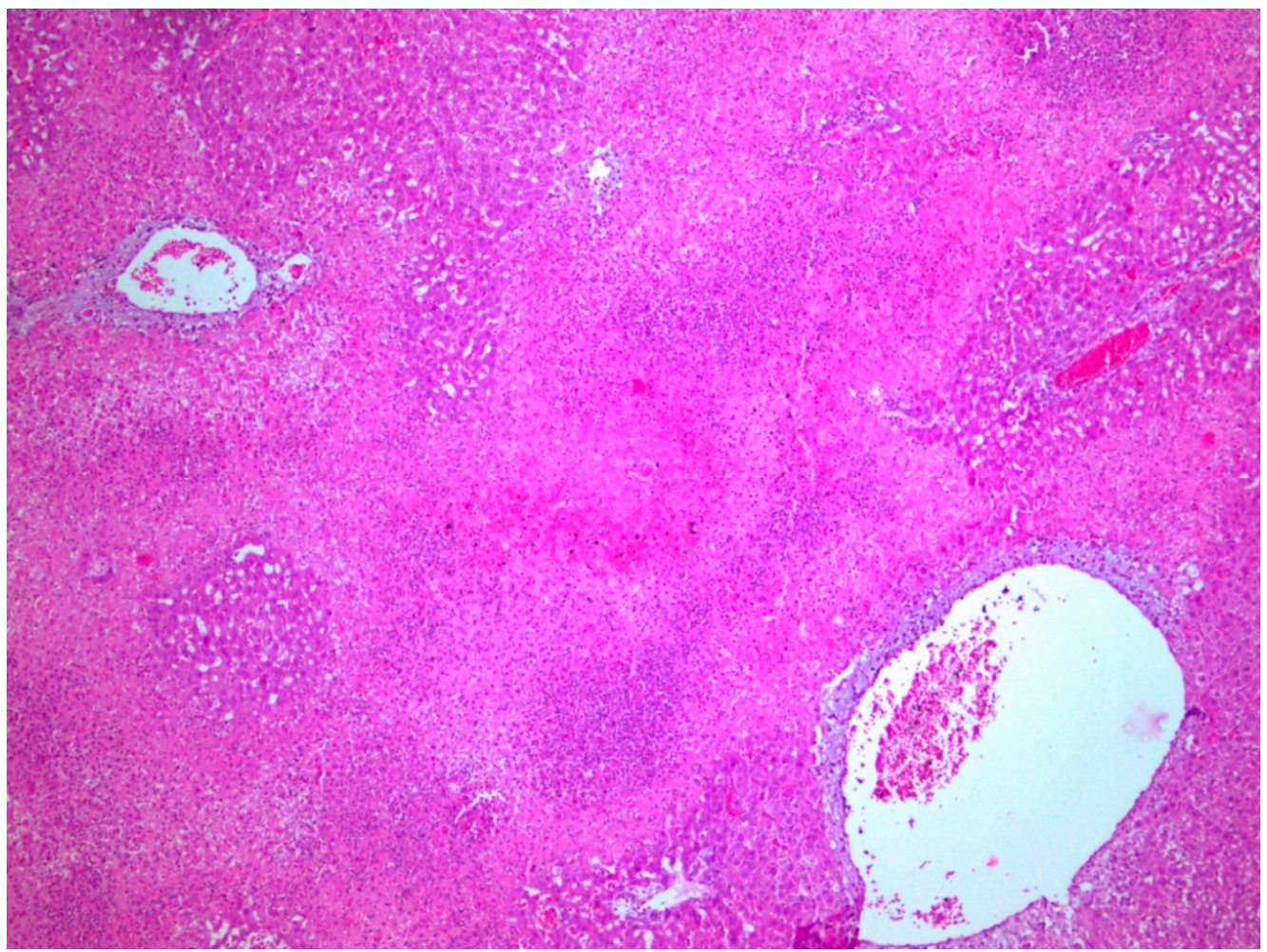

(B1) The hepatic histological aspect of group IV; HE staining, 5×.

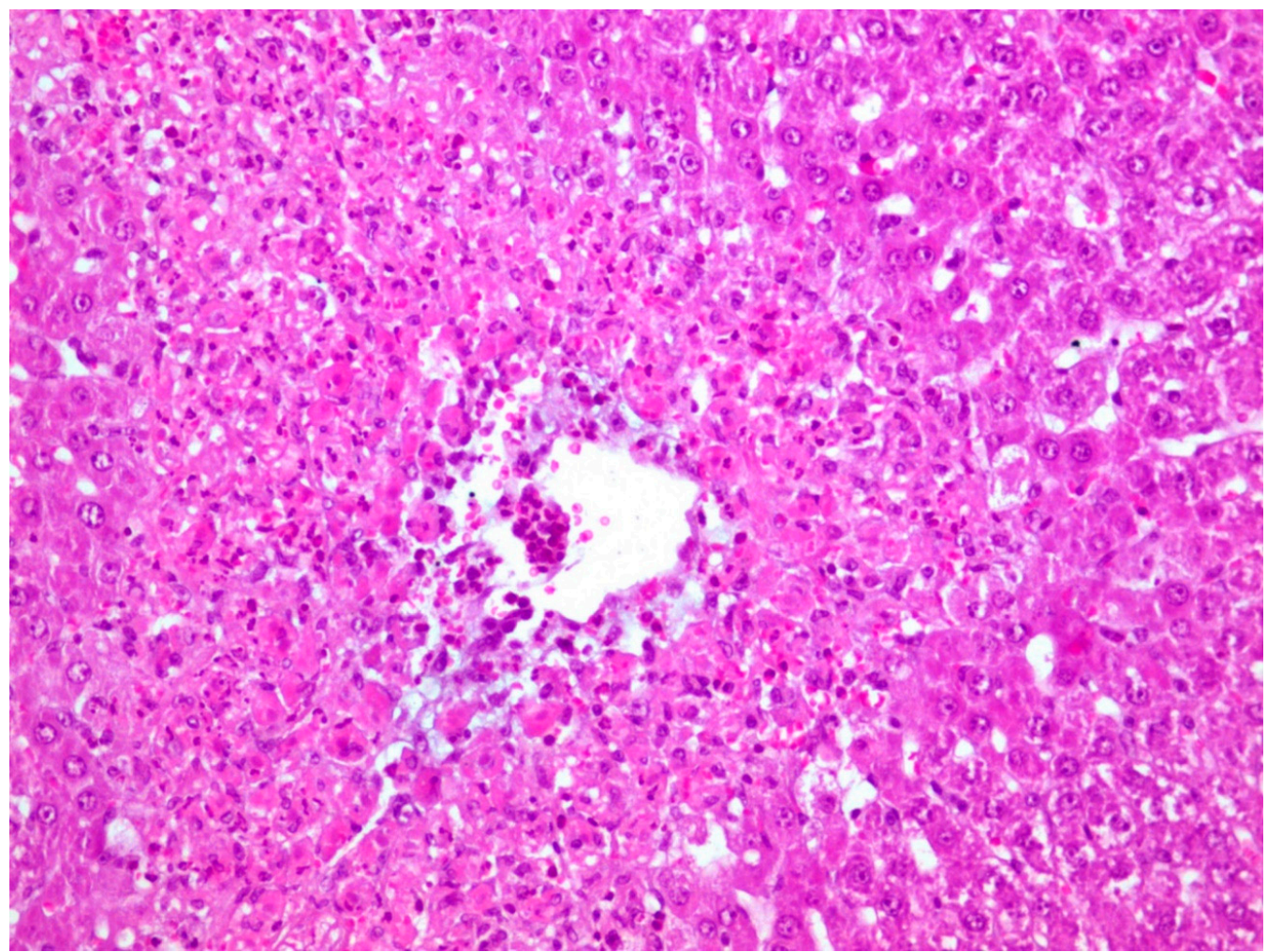

(B2) The hepatic histological aspect of group IV; HE staining, 20×.

Figure 4. Cont. 


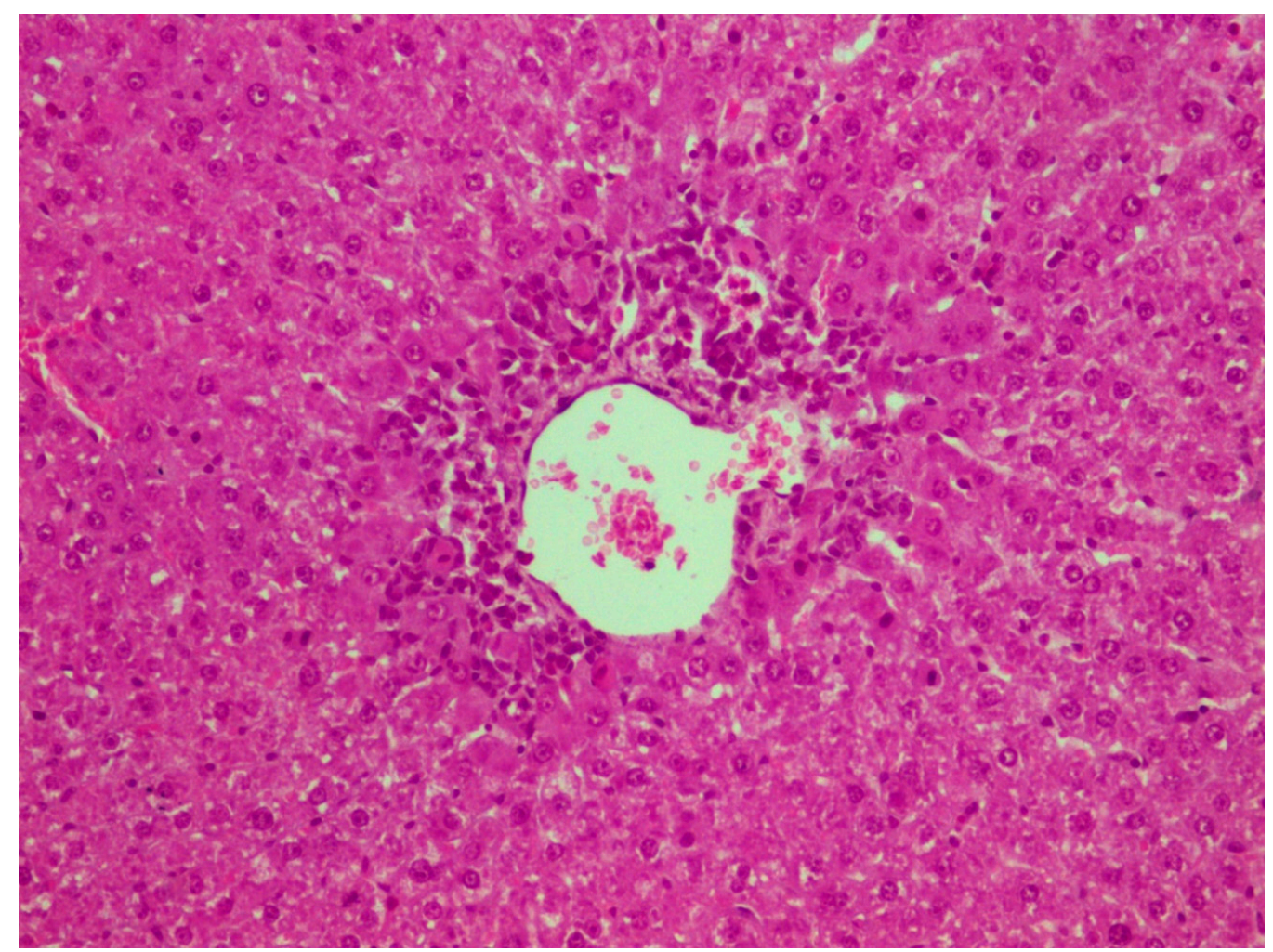

(C1) The hepatic histological aspect of group V; HE staining, 20×.

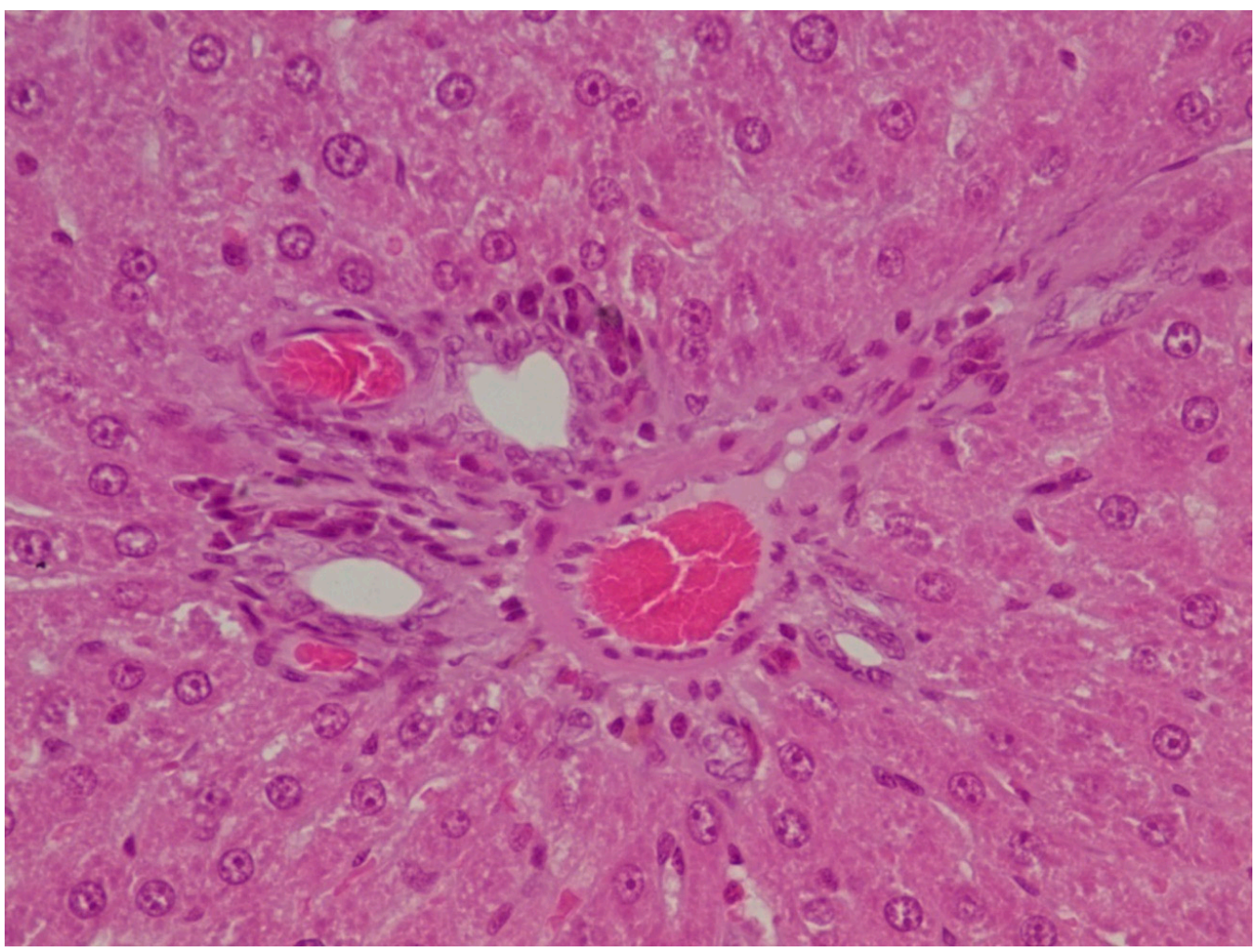

(C2) The hepatic histological aspect of group V; HE staining, 40×.

Figure 4. Cont. 


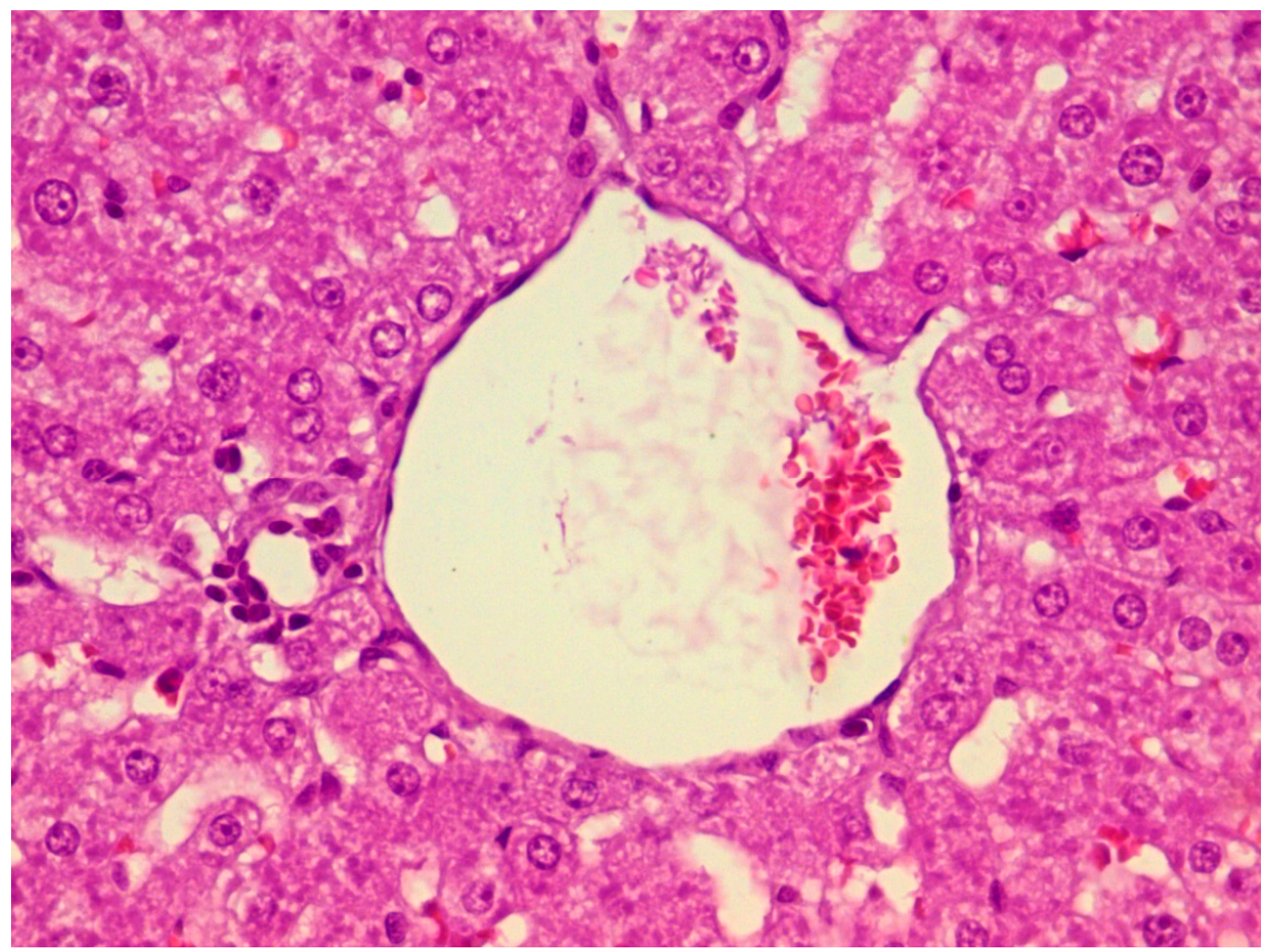

(D1) The hepatic histological aspect of group VI; HE staining, 40×.

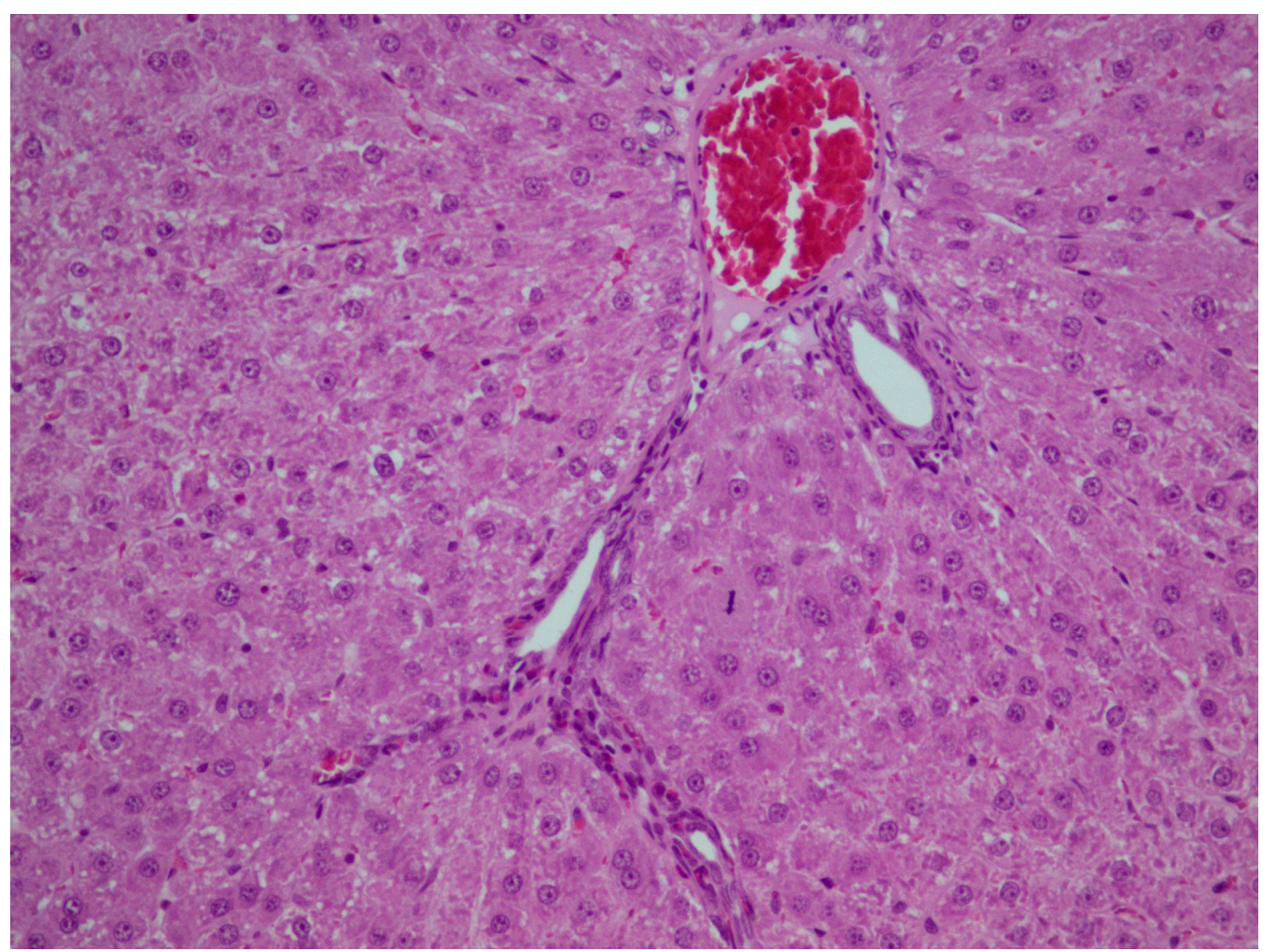

(D2) The hepatic histological aspect of group VI; HE staining, 20×.

Figure 4. Cont. 


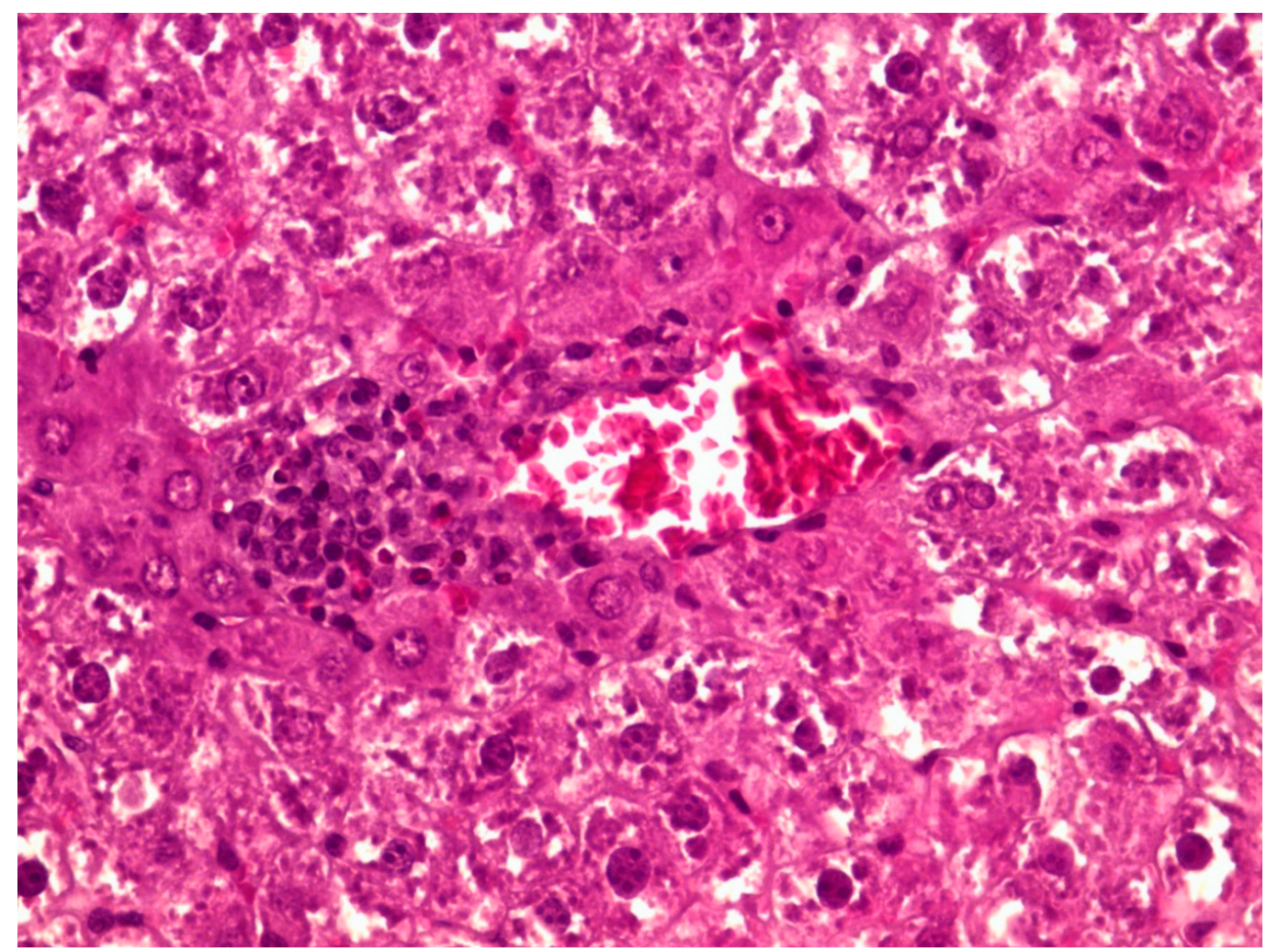

(E1) The hepatic histological aspect of group VII; HE staining, 40×.

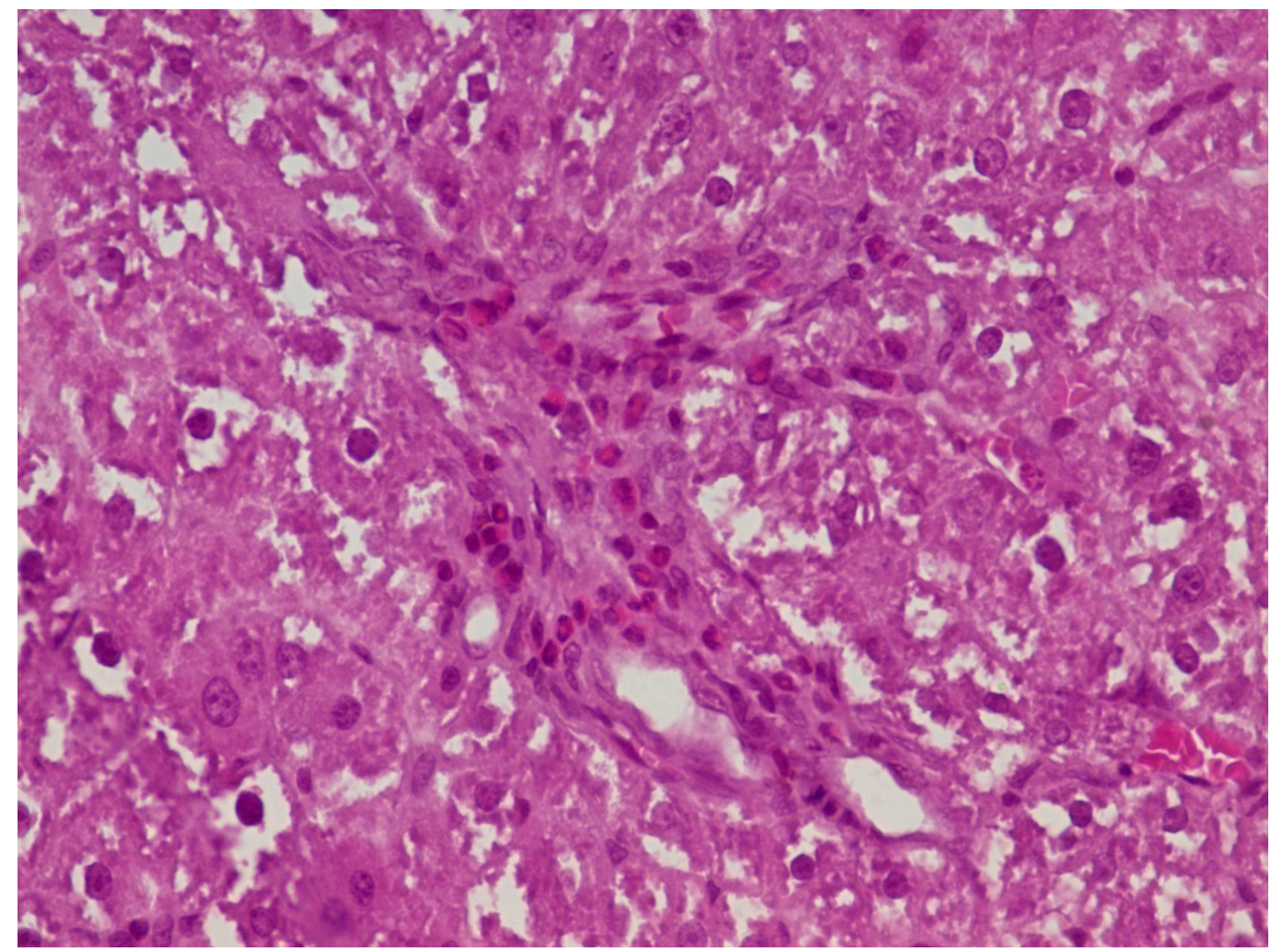

(E2) The hepatic histological aspect of group VII; HE staining, 40×.

Figure 4. Rats were treated with $1 \%$ CMC, APAP, MSB or silymarin either alone or in various combinations (as indicated). Livers were collected after 13 days, formalin-fixed, and embedded in 
paraffin. Tissue sections were then stained with hematoxylin and eosin and examined for signs of inflammation and liver damage. Control/CMC (group I), (A) APAP (group IV), (B) APAP + silymarin (group V), (C) APAP + MSB (group VI), (D) APAP + silymarin + MSB (group VII), (E) groups of rats. Abbreviations: APAP, N-acetyl-p-aminophenol or paracetamol (acetaminophen); CMC, carboxymethylcellulose; MSB, MegaSporeBiotic ${ }^{\mathrm{TM}}$.

\subsection{Effect of MegaSporeBiotic ${ }^{\mathrm{TM}}$ and Silymarin on Tight Junction}

The tight integrity of the junction was evaluated by quantifying the expression of ZO-1, a major TJ protein. ZO-1 increased significantly after APAP administration, and silymarin and MSB significantly reduced its level (Figure 5).

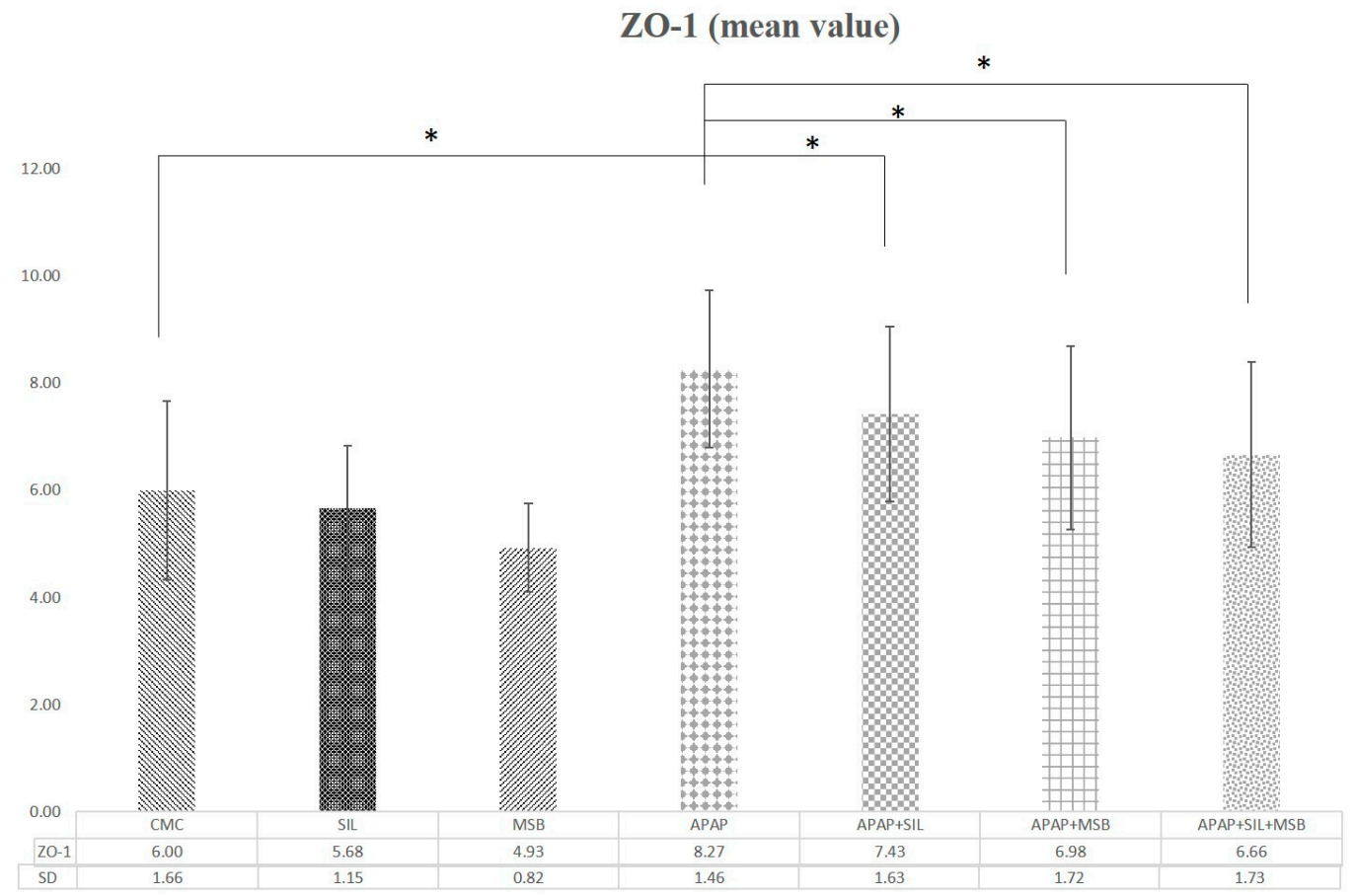

Figure 5. Changes in tight junction protein (ZO-1) levels. Rats were treated with $1 \% \mathrm{CMC}, \mathrm{SIL}, \mathrm{MSB}$, APAP, APAP + SIL, APAP + MSB or APAP + SIL + MSB. Periorbital blood was collected on Day 13 and the serum was tested for ZO-1 levels. * Significant difference $(p<0.05)$ between groups; data were analyzed using one-way ANOVA. Abbreviations: APAP, N-acetyl-p-aminophenol or paracetamol (acetaminophen); CMC, carboxymethylcellulose; MSB, MegaSporeBiotic ${ }^{\mathrm{TM}}$; SIL, silymarin; ZO-1, zonula occludens.

\section{Discussion}

In this study, we examined, for the first time, the effect of probiotic spores (MSB) on acute hepatic injury induced by APAP in rats. APAP-induced hepatotoxicity is a classic and well known experimental model that is used to evaluate the hepatoprotective activity of nutraceuticals. Biochemical data obtained in the present study demonstrated that MSB pretreatment ameliorated APAP-induced acute liver injury. Also, histopathological hepatic injury was improved by preadministration of MSB or silymarin versus the disease model group (APAP alone).

As expected, there were no differences between the groups I-III (control, silymarin and MSB) in terms of liver enzyme levels (AST, ALT) ( $p>0.05$ vs. group IV). However, significant differences were observed between the APAP group (group IV) and groups pretreated with silymarin, MSB or both (groups V, VI and VII, respectively); AST and ALT levels were significantly reduced in groups V, VI and VII compared to group IV. 
Regarding histopathological aspects, no changes were observed in groups I-III, but hepatic necrosis occurred in livers from the APAP group (group IV, positive control). Significant improvements (vs. group IV) were observed in rats pretreated with silymarin (group V), MSB (group VI) or both (group VII). However, the pretreated MSB group (group VI) had the best hepatic protection (vs. groups $\mathrm{V}$ and VII). Structural changes in the liver sections were minimal.

APAP-induced hepatotoxicity is associated with oxidative stress in the liver. APAP is metabolized to a reactive (toxic) metabolite, NAPQI, which is efficiently detoxified by GSH, a nonenzymatic antioxidant (an antioxidant molecule with a low-molecular-weight) that acts as a free-radical scavenger [20]. Administration of APAP in high doses leads to a high amount of NAPQI followed by GSH depletion [21]. GSH deficiency increases the production of reactive oxygen species (ROS), and consequently, oxidative stress in the liver [22]. Cell lesions (inflammation, apoptosis) and then cell death occurs due to oxidative stress [4]. Our study reported that APAP overdose causes TAC to slowly decrease compared to the control group, but pretreatment with silymarin and MSB increases TAC levels. There are no differences between APAP groups and silymarin compared to APAP and MSB.

Although there is not much information about probiotics and their antioxidant and hepatoprotective effects, it is known that Bacillus sp produce exopolysaccharide (ESP) and has significant antioxidant and immunoregulatory activities. EPS production by B. coagulans has significant in vitro antioxidant activity $[23,24]$. Moreover, Duc et al. has shown that Bacillus spore-forming bacteria have the ability to produce carotenoids [25], which have strong antioxidant properties. This effect is very important in humans because they are not able to synthesize carotenoids [26]. Rana et al. demonstrated that carotenoid supplementation increases GSH levels (in liver and blood) in experimentally induced hepatotoxicity in rats. Increased levels of GSH induced by carotenoids indicate the protection of hepatocytes in rats with drug-induced hepatotoxicity [27]. Most likely, MSB is able to restore the balance between ROS and antioxidants through the contained Bacillus sp and as such, reduces APAP-induced liver damage. B. subtilis HU36 is a well-studied, unique, patented, Gram-positive, spore-forming bacteria strain that produces a distinct yellow-orange pigmentation. The pigmentation is due to the synthesis of carotenoids; which are gastric stable, bio-accessible, and significantly more bioavailable than carotenoids from other sources, such as lycopene, lutein, astaxanthin, zeaxanthin and beta-carotene; as well as essential vitamins $\mathrm{B}$ and $\mathrm{K} 2$ [28].

Leaky gut syndrome is characterized by the dysfunction or disruption of the intestinal barrier. When this happens, toxins such as endotoxins (lipopolysaccharide; LPS) are translocated to the lamina propria and may subsequently lead to many diseases [29]. Duysburgh et al. showed that Bacillus spores coadministered with prebiotics in a symbiotic formula, significantly influenced the microbial activity in the intestine, increasing the production of colonic butyrate. This is an important short-chain fatty acid that helps retain the structure of the intestinal barrier and blocks aberrant expression of ZO-1, thus decreasing endotoxemia [30].

Tight junction (TJ) proteins are pivotal structures in maintaining the function of the mucosal barrier. It has been shown that ZO-1 expression increased after liver injury (ischemia/reperfusion) and butyrate reversed this aberrant expression. Thus, butyrate may have a protective effect on TJ proteins after reperfusion injury with intestinal congestion [31].

In the current study, we found elevated plasma concentrations of ZO-1 in the groups of rats treated with APAP overdose compared with groups without APAP or with those receiving APAP in combination with silymarin, MSB or both. The changes were positively correlated to levels of other proinflammatory cytokines (TNF- $\alpha$, IL-1 $\beta$ ).

A similar correlation between systemic ZO-1 levels and an inflammatory marker (C-reactive protein; CRP) was observed in patients with cirrhosis [32]. Moreover, in intensive care unit patients, the systemic level of ZO-1 was correlated with sepsis severity or multiple organ dysfunction scores [33].

Recently, APAP has been shown to induce disruption of cell-cell TJs in the livers of mice and human hepatic cells, even at low doses [34]. Thus, APAP in high doses may increase endotoxemia, which could, in turn, increase systemic inflammation. It was demonstrated that supplementation with 
a spore-based probiotic (Bacillus sp) reduced the characteristic symptoms of leaky gut syndrome [35] which suggests that our study product (MSB) may strengthen the intestinal barrier and therefore decrease the dissemination of microbial-derived compounds from the intestine (including toxins) due to inflammation-triggered leaky gut, ultimately decreasing endotoxemia. Moreover, by restoring the intestinal barrier, MSB may prevent inflammation.

It is known that once LPS enters the portal vein, it interacts with TLR4 on Kupffer cells. This interaction leads to an elevation of LPS-TLR4-related proinflammatory cytokines. TNF- $\alpha$ is considered the first mediator that is increased, followed by IL-10 and IL-6 [36,37]. Over 20 years ago, Blazka et al. demonstrated a significant increase in serum TNF- $\alpha$ levels after administration of APAP; they also observed that the administration of Kupffer cell inhibitors reduced APAP toxicity in rats [38]. Concerning liver inflammation, MSB decreased the level of proinflammatory cytokines (TNF- $\alpha$, IL-6) similar to silymarin in APAP-treated animals; the combination of MSB and silymarin reduced TNF- $\alpha$ and IL-6 to normal levels. These results suggest that MSB may also have had an anti-inflammatory effect on rats that were intoxicated with APAP; also, group IV (APAP) presented with severe histopathological hepatic inflammation (necrosis). The other groups pretreated with silymarin, MSB or both (groups V, VI and VII, respectively), exhibited inflammatory eosinophilic infiltrates and lymphocytes either without hepatitis or with mild interface hepatitis. These changes were accompanied by changes in ALT and AST levels. It is likely that MSB has the capacity to change the level of proinflammatory cytokines produced in response to APAP overdose. It was demonstrated that B. coagulans decreased the TNF- $\alpha$ similarly to indomethacin in an experimental rat model of rheumatoid arthritis [39], and B. clausii inhibited the secretion of proinflammatory cytokines (TNF- $\alpha$, IL-6, IL-17) and increased levels of anti-inflammatory cytokines (IL-10) in a postmenopausal osteoporotic mouse model [40].

\section{Conclusions}

In conclusion, our study revealed that the probiotic supplement, MSB, which contains Bacillus sp spores, had a protective effect on acute hepatic injury induced by APAP overdose in rats. Pretreatment with MSB resulted in a significant reduction in serum AST, ALT, proinflammatory cytokines (TNF- $\alpha$, IL- $1 \beta$ ), ZO-1 and TAC, as well as hepatocyte necrosis, which was similar to the well-known hepatoprotective agent, silymarin. These results indicate the hepatoprotective potential of this spore-based probiotic in drug-induced acute hepatotoxicity. It is very important in drug-induced liver toxicity. However, further studies are needed to confirm this in humans.

Author Contributions: Conceptualization, M.A.N., A.C. and A.D.B.; methodology, M.A.N., M.R.P., C.I.B.; validation, D.M.M., M.R.P., C.I.B. and E.C.B.; writing-original draft preparation, A.C., D.M.M.; writing一review and editing, M.A.N., A.C.; supervision, A.D.B. All authors have read and agreed to the published version of the manuscript.

Funding: This research received no external funding.

Conflicts of Interest: The authors declare no conflict of interest.

\section{References}

1. Pandit, A.; Sachdeva, T.; Bafna, P. Drug-induced hepatotoxicity: A review. J. Appl. Pharm. Sci. 2012, 2, 233-243. [CrossRef]

2. Ghanem, C.I.; Pérez, M.J.; Manautou, J.E.; Mottino, A.D. Acetaminophen from liver to brain: New insights into drug pharmacological action and toxicity. Pharmacol. Res. 2016, 109, 119-131. [CrossRef] [PubMed]

3. Chaudhuri, S.; Mccullough, S.S.; Hennings, L.; Letzig, L.; Simpson, P.M.; Hinson, J.A.; James, L.P. Acetaminophen hepatotoxicity and HIF-1 $\alpha$ induction in acetaminophen toxicity in mice occurs without hypoxia. Toxicol. Appl. Pharmacol. 2011, 252, 211-220. [CrossRef] [PubMed]

4. Cha, H.; Lee, S.; Lee, J.H.; Park, J.W. Protective effects of p-coumaric acid against acetaminophen-induced hepatotoxicity in mice. Food Chem. Toxicol. 2018, 121, 131-139. [CrossRef] [PubMed]

5. Wang, L.; Li, X.; Chen, C. Inhibition of acetaminophen-induced hepatotoxicity in mice by exogenous thymosin $\beta 4$ treatment. Int. Immunopharmacol. 2018, 61, 20-28. [CrossRef] 
6. Fouad, A.A.; Jresat, I. Hepatoprotective effect of coenzyme Q10 in rats with acetaminophen toxicity. Environ. Toxicol. Pharmacol. 2012, 33, 158-167. [CrossRef]

7. Abdeen, A.; Abdelkader, A.; Abdo, M.; Wareth, G.; Aboubakr, M.; Aleya, L.; Abdel-Daim, M. Protective effect of cinnamon against acetaminophen-mediated cellular damage and apoptosis in renal tissue. Environ. Sci. Pollut. Res. 2019, 26, 240-249. [CrossRef]

8. Abdel-Daim, M.; Abushouk, A.I.; Reggi, R.; Yarla, N.S.; Palmery, M.; Peluso, I. Association of antioxidant nutraceuticals and acetaminophen (paracetamol): Friend or foe? J. Food Drug Anal. 2018, 26, S78-S87. [CrossRef]

9. Usami, M.; Miyoshi, M.; Yamashita, H. Gut microbiota and host metabolism in liver cirrhosis. World J. Gastroenterol. 2015, 21, 11597-11608. [CrossRef]

10. Altamirano-Barrera, A.; Uribe, M.; Chávez-Tapia, N.C.; Nuño-Lámbarri, N. The role of the gut microbiota in the pathology and prevention of liver disease. J. Nutr. Biochem. 2018, 60,1-8. [CrossRef]

11. Catinean, A.; Neag, M.A.; Mitre, A.O.; Bocsan, C.I.; Buzoianu, A.D. Microbiota and Immune-Mediated Skin Diseases-An Overview. Microorganisms 2019, 7, 279. [CrossRef] [PubMed]

12. Dawood, M.A.O.; Koshio, S.; Abdel-Daim, M.M.; Van Doan, H. Probiotic application for sustainable aquaculture. Rev. Aquac. 2019, 11, 907-924. [CrossRef]

13. El-Khadragy, M.F.; Al-Olayan, E.M.; Elmallah, M.I.Y.; Alharbi, A.M.; Yehia, H.M.; Abdel Moneim, A.E. Probiotics and yogurt modulate oxidative stress and fibrosis in livers of Schistosoma mansoni-infected mice. BMC Complement. Altern. Med. 2019, 19, 1-13. [CrossRef] [PubMed]

14. Fan, L.; Hou, F.; Muhammad, A.I.; Ruiling, L.V.; Watharkar, R.B.; Guo, M.; Ding, T.; Liu, D. Synergistic inactivation and mechanism of thermal and ultrasound treatments against Bacillus subtilis spores. Food Res. Int. 2019, 116, 1094-1102. [CrossRef] [PubMed]

15. Shinde, T.; Vemuri, R.; Shastri, M.D.; Perera, A.P.; Tristram, S.; Stanley, R.; Eri, R. Probiotic Bacillus coagulans MTCC 5856 spores exhibit excellent in-vitro functional efficacy in simulated gastric survival, mucosal adhesion and immunomodulation. J. Funct. Foods 2019, 52, 100-108. [CrossRef]

16. Catinean, A.; Neag, A.M.; Nita, A.; Buzea, M.; Buzoianu, A.D. Bacillus spp. spores-a promising treatment option for patients with irritable bowel syndrome. Nutrients 2019, 11, 1968. [CrossRef] [PubMed]

17. Jafari, M.; Mortazavian, A.M.; Hosseini, H.; Safaei, F.; Mousavi Khaneghah, A.; Sant'Ana, A.S. Probiotic Bacillus: Fate during sausage processing and storage and influence of different culturing conditions on recovery of their spores. Food Res. Int. 2017, 95, 46-51. [CrossRef] [PubMed]

18. Foligné, B.; Peys, E.; Vandenkerckhove, J.; Van hemel, J.; Dewulf, J.; Breton, J.; Pot, B. Spores from two distinct colony types of the strain Bacillus subtilis PB6 substantiate anti-inflammatory probiotic effects in mice. Clin. Nutr. 2012, 31, 987-994.

19. Erel, O. A novel automated direct measurement method for total antioxidant capacity using a new generation, more stable ABTS radical cation. Clin. Biochem. 2004, 37, 277-285. [CrossRef]

20. Spyropoulos, B.G.; Misiakos, E.P.; Fotiadis, C.; Stoidis, C.N. Antioxidant properties of probiotics and their protective effects in the pathogenesis of radiation-induced enteritis and colitis. Dig. Dis. Sci. 2011, 56, 285-294. [CrossRef]

21. Li, G.; Chen, J.B.; Wang, C.; Xu, Z.; Nie, H.; Qin, X.Y.; Chen, X.M.; Gong, Q. Curcumin protects against acetaminophen-induced apoptosis in hepatic injury. World J. Gastroenterol. 2013, 19, 7440-7446. [CrossRef] [PubMed]

22. Madkour, F.F.; Abdel-Daim, M.M. Hepatoprotective and Antioxidant Activity of Dunaliella salina in Paracetamol-induced Acute Toxicity in Rats. Indian J. Pharm. Sci. 2013, 75, 642. [PubMed]

23. Zheng, L.P.; Zou, T.; Ma, Y.J.; Wang, J.W.; Zhang, Y.Q. Antioxidant and DNA damage protecting activity of exopolysaccharides from the endophytic bacterium Bacillus Cereus SZ1. Molecules 2016, 21, 174. [CrossRef] [PubMed]

24. Kodali, V.P.; Sen, R. Antioxidant and free radical scavenging activities of an exopolysaccharide from a probiotic bacterium. Biotechnol. J. 2008, 3, 245-251. [CrossRef] [PubMed]

25. Duc, L.H.; Fraser, P.D.; Tam, N.K.M.; Cutting, S.M. Carotenoids present in halotolerant Bacillus spore formers. FEMS Microbiol. Lett. 2006, 255, 215-224. [CrossRef]

26. Kulczyński, B.; Gramza-Michałowska, A.; Kobus-Cisowska, J.; Kmiecik, D. The role of carotenoids in the prevention and treatment of cardiovascular disease-Current state of knowledge. J. Funct. Foods 2017, 38, $45-65$. 
27. Rana, S.V.; Pal, R.; Vaiphei, K.; Ola, R.P.; Singh, K. Hepatoprotection by carotenoids in isonia-Rifampicin induced hepatic injury in rats. Biochem. Cell Biol. 2010, 88, 819-834. [CrossRef]

28. Crescenzo, R.; Mazzoli, A.; Cancelliere, R.; Bucci, A.; Naclerio, G.; Baccigalupi, L.; Cutting, S.M.; Ricca, E.; Iossa, S. Beneficial effects of carotenoid-producing cells of Bacillus indicus HU16 in a rat model of diet-induced metabolic syndrome. Benef. Microbes 2017, 8, 823-831. [CrossRef]

29. Tetz, G.; Tetz, V. Bacteriophage infections of microbiota can lead to leaky gut in an experimental rodent model. Gut Pathog. 2016, 8, 1-4. [CrossRef]

30. Duysburgh, C.; Van den Abbeele, P.; Krishnan, K.; Bayne, T.F.; Marzorati, M. A synbiotic concept containing spore-forming Bacillus strains and a prebiotic fiber blend consistently enhanced metabolic activity by modulation of the gut microbiome in vitro. Int. J. Pharm. X 2019, 1, 100021. [CrossRef]

31. Liu, B.; Qian, J.; Wang, Q.; Wang, F.; Zhenyu, M.; Qiao, Y. Butyrate protects rat liver against total hepatic ischemia reperfusion injury with bowel congestion. PLoS ONE 2014, 9, e106184. [CrossRef] [PubMed]

32. Karthikeyan, A.; Mohan, P.; Chinnakali, P.; Vairappan, B. Elevated systemic zonula occludens 1 is positively correlated with inflammation in cirrhosis. Clin. Chim. Acta 2018, 480, 193-198. [CrossRef] [PubMed]

33. Zhao, G.J.; Li, D.; Zhao, Q.; Lian, J.; Hu, T.T.; Hong, G.L.; Yao, Y.M.; Lu, Z.Q. Prognostic value of plasma tight-junction proteins for sepsis in emergency department: An observational study. Shock 2016, 45, 326-332. [CrossRef]

34. Gamal, W.; Treskes, P.; Samuel, K.; Sullivan, G.J.; Siller, R.; Srsen, V.; Morgan, K.; Bryans, A.; Kozlowska, A.; Koulovasilopoulos, A.; et al. Low-dose acetaminophen induces early disruption of cell-cell tight junctions in human hepatic cells and mouse liver. Sci. Rep. 2017, 7,1-16. [CrossRef]

35. McFarlin, B.K.; Henning, A.L.; Bowman, E.M.; Gary, M.A.; Carbajal, K.M. Oral spore-based probiotic supplementation was associated with reduced incidence of post-prandial dietary endotoxin, triglycerides, and disease risk biomarkers. World J. Gastrointest. Pathophysiol. 2017, 8, 117. [CrossRef]

36. Cai, Y.; Lu, D.; Zou, Y.; Zhou, C.; Liu, H.; Tu, C.; Li, F.; Liu, L.; Zhang, S. Curcumin Protects Against Intestinal Origin Endotoxemia in Rat Liver Cirrhosis by Targeting PCSK9. J. Food Sci. 2017, 82, 772-780. [CrossRef]

37. van Lier, D.; Geven, C.; Leijte, G.P.; Pickkers, P. Experimental human endotoxemia as a model of systemic inflammation. Biochimie 2019, 159, 99-106. [CrossRef]

38. Blazka, M.E.; Elwell, M.R.; Holladay, S.D.; Wilson, R.E.; Luster, M.I. Histopathology of Acetaminophen-Induced Liver Changes: RolE of Interleukin $1 \alpha$ and Tumor Necrosis Factor $\alpha$. Toxicol. Pathol. 1996, 24, 181-189. [CrossRef]

39. Abhari, K.; Shekarforoush, S.S.; Hosseinzadeh, S.; Nazifi, S.; Sajedianfard, J.; Eskandari, M.H. The effects of orally administered Bacillus coagulans and inulin on prevention and progression of rheumatoid arthritis in rats. Food Nutr. Res. 2016, 60, 30876. [CrossRef]

40. Dar, H.Y.; Pal, S.; Shukla, P.; Mishra, P.K.; Tomar, G.B.; Chattopadhyay, N.; Srivastava, R.K. Bacillus clausii inhibits bone loss by skewing Treg-Th17 cell equilibrium in postmenopausal osteoporotic mice model. Nutrition 2018, 54, 118-128. [CrossRef]

(C) 2020 by the authors. Licensee MDPI, Basel, Switzerland. This article is an open access article distributed under the terms and conditions of the Creative Commons Attribution (CC BY) license (http://creativecommons.org/licenses/by/4.0/). 